\title{
POLÍTICAS DETERMINANTES AO PROCESSO DE MODERNIZAÇÃO AGRÍCOLA NO CENTRO-OESTE BRASILEIRO
}

\section{KEY POLICIES FOR THE AGRICULTURAL MODERNIZATION PROCESS IN THE BRAZILIAN MIDWEST}

\author{
Danillo Alves de Oliveira ${ }^{1}$ \\ Alcido Elenor Wander ${ }^{2}$ \\ Paulo Cesar Bontempo ${ }^{3}$ \\ Claudecir Gonçales ${ }^{4}$ \\ Cidonea Machado Deponti ${ }^{5}$
}

\section{RESUMO}

Este trabalho buscou apresentar e discutir os principais fatores e elementos de ordem política e econômica determinantes na condução do processo de modernização das estruturas agrícolas nos estados que compõem a região do Centro-Oeste brasileiro, fundamentalmente ocorrido no período compreendido entre as décadas de 1960 e 1980. Para tanto, foi analisado um conjunto de políticas instituídas pelos governos durante o período mencionado, como a política de crédito rural, a política de garantia de preços mínimos, a política cambial, a expansão da rede rodoviária e o fomento ao desenvolvimento da pesquisa e extensão rural. Além disso, ainda foi abordada a participação do Estado pela implantação das políticas de desenvolvimento regional, como a criação da Agência de Desenvolvimento do Centro-Oeste e dos planos de diversificação produtiva, denominados programas especiais. E, por fim, foram examinados alguns dados estatísticos que buscaram evidenciar a efetividade da aplicação das políticas explanadas no decorrer do texto.

Palavras-chaves: Centro-Oeste. Desenvolvimento Regional. Estado. Modernização Agrícola. Políticas.

\begin{abstract}
This study aimed to present and discuss the key political and economic factors and elements driving the modernization of agricultural structures in those states that make up the Brazilian Midwest region, primarily within the period between the 1960s and 1980s. To that end, we analyzed a set of policies introduced by governments during that period, such as rural credit policy, the minimum price guarantee policy, exchange rate policy, the expansion of the road network, and promotion of research development and rural extension. In addition, the participation of the state for the implementation of regional development policies was also discussed, such as the creation of the Midwest Development Agency and productive diversification plans, called special programs. And finally, we examined some statistical data that sought to demonstrate the effectiveness of the execution of those policies explained throughout the text.
\end{abstract}

Keywords: Midwest. Regional development. State. Agricultural modernization. Policies.

\footnotetext{
${ }^{1}$ Universidade de Santa Cruz do Sul (UNISC). Discente do Programa de Pós-graduação em Desenvolvimento Regional (Doutorado) pela UNISC - Avenida Independência, 2293 - Universitário, Santa Cruz do Sul, RS - CEP: 96815-900. E-mail: danillocomp@hotmail.com

${ }^{2}$ Faculdades Alves Faria (ALFA). Professor do Programa de Pós-Graduação em Desenvolvimento Regional e Administração das Faculdades ALFA - Av. Perimetral Norte, 4129 - Vila Joao Vaz, Goiânia, GO - CEP: 74445-190. E-mail: alcidowander@msn.com ${ }^{3}$ Faculdades Alves Faria (ALFA). Professor e pesquisador do Programa de Pós-Graduação em Desenvolvimento Regional e Administração das Faculdades ALFA - Av. Perimetral Norte, 4129 - Vila Joao Vaz, Goiânia, GO - CEP: 74445-190. E-mail: pcbontempo@ajato.com.br

${ }^{4}$ Instituto Federal Goiano (IFG). Professor e Pró-reitor de Administração do IFG - Av. Wilton Monteiro da Rocha, S/n - Setor Cristina II, GO - CEP: 75380-000. E-mail: claudecirg@gmail.com

${ }^{5}$ Universidade de Santa Cruz do Sul (UNISC). Professora e pesquisadora do Programa de Pós-graduação em Desenvolvimento Regional da UNISC - Avenida Independência, 2293 - Universitário, Santa Cruz do Sul, RS - CEP: 96815-900. E-mail: cidonea@yahoo.com.br
} 


\section{Introdução}

Ao adentrar a segunda metade do século XX, mais especificamente a partir da década de 1960, o Centro-Oeste brasileiro passou por significativas transformações na base da cadeia produtiva que se fundaram sob um processo de modernização da atividade rural, sendo tal ação alcançada por meio de investimentos em tecnologia agrícola, essencialmente caracterizada pela utilização de fertilizantes, defensivos, mecanização e assistência técnica especializada.

Nessa fase, houve uma efetiva participação do Estado por meio da implantação de um conjunto de Políticas de Governo e criação de Programas Especiais, que visavam o fortalecimento do setor agrícola, cujos esforços se centraram no cerceamento da concessão de crédito rural, política de preço mínimo, desvalorização cambial, pesquisa e extensão rural, além da ampliação da malha de transporte rodoviário, que facilitou a integração da região Centro-Oeste às demais regiões do país, principalmente com o Sul e Sudeste.

As mudanças provocadas pela dinâmica de modernização agrícola foram rapidamente percebidas ainda no início da década de 1970 por meio da expressiva expansão das áreas de lavoura, ocorrida simultaneamente com a abertura das terras no Cerrado, que passaram a receber as culturas de arroz, feijão, milho, algodão, soja, e sorgo, tudo isso em concomitância com o exercício da atividade de pecuária, já estabelecida em períodos anteriores. Tais acontecimentos tornaram-se decisivos não apenas para a diversificação da produção agrícola primária, mas também para a formação de alguns espaços regionais que nas décadas seguintes se transformariam em centros para o processo de desenvolvimento rural.

O objetivo deste trabalho concentra-se em apresentar uma abordagem de ordem teórica e analítica dos principais fatores e elementos de ordem política econômica que resultaram nesse processo de modernização da atividade agrícola, cuja trajetória se estabeleceu com um forte e importante apoio do Estado, através da elaboração e aplicação de um conjunto de políticas. Nesse sentido, será utilizada a contribuição literária de diversos autores, além de dados censitários extraídos do Instituto Brasileiro de Geografia e Estatística (IBGE). 


\section{Fatores determinantes do processo de modernização agrícola}

Durante a década de 1960 o embate político sobre o modelo de desenvolvimento rural brasileiro esteve alicerçado sobre dois pilares. O primeiro deles está relacionado com a questão da reforma agrária, sob o argumento de que tal instrumento consentiria aos trabalhadores maior acesso ao fator de produção terra. $\mathrm{O}$ segundo refere-se a outra linha de análise da questão, que consistia no raciocínio da modernização da agricultura, voltada especialmente para o desenvolvimento do complexo urbano-industrial por meio do crescimento incremental do quantitativo produtivo, concebido por investimentos em tecnologia agrícola e efetivado pela adoção do uso de fertilizantes, agrotóxicos, mecanização e orientação técnica (GONÇALVES NETO, 1997).

E foi com base no modelo de modernização das estruturas agrícolas que ocorreram as transformações no meio rural a partir das décadas de 1960 e 1970, promovidas essencialmente por um processo de adoção tecnológica no desenvolvimento das atividades do campo, e incrementadas de forma que propiciassem ganhos de produtividade pelo rendimento na produção e incentivadas por um conjunto de políticas que tinham por objetivo fomentar a criação de uma infraestrutura necessária ao exercício desse decurso.

Bacha (2004) esclarece que o conjunto de políticas que fortaleceram o setor agrícola na década de 1970 começou a ser estruturado ainda no final da década anterior, através da determinação de algumas medidas governamentais, tendo por instrumento dessa ação a criação de políticas de crédito rural e preços mínimos, a desvalorização cambial, a ampliação da rede rodoviária brasileira, além de investimentos em pesquisa e extensão rural.

\subsection{A política de crédito rural}

Gonçalves Neto (1997) comenta que o exercício da atividade econômica exige determinada quantidade de recursos financeiros disponíveis para ser empregados na forma de capital de giro e na realização dos investimentos solicitados ao desenvolvimento do empreendimento, observando-se, nesse contexto, que o volume necessário está diretamente vinculado à forma de produção e à produtividade desejada. 
Com relação às políticas de crédito rural, Bacha (2004) destaca que a primeira instituição a fornecer esse tipo de recurso foi o Banco do Brasil em 1937, o que foi permitido por meio da formação de uma carteira de crédito iniciada ainda em 1935, denominada Carteira de Crédito Agrícola e Industrial (CREAI), em que se especificava que o expressivo crescimento do quantitativo de crédito somente ocorreu após 1965, quando então foi criado o Sistema Nacional de Crédito Rural, também conhecido pela sigla SNCR, que, segundo Szmrecsányi (apud BELLUZZO; COUTINHO, 1998, p. 259), “[...] cujo funcionamento está subordinado às normas e resoluções do Conselho Monetário Nacional e do Banco Central do Brasil”.

A origem dos recursos financeiros destinados ao crédito rural pode ser demonstrada conforme Arantes e Bastos (apud PEREIRA, 2004, p. 671),

Como fonte de recursos destacam-se as dotações orçamentárias com destinação específica, do Fundo Nacional de Refinanciamento Rural, Fundo Nacional de Reforma Agrária e Fundo Agroindustrial de Reconversão, recurso nunca inferiores a $10 \%$ dos depósitos de qualquer natureza dos bancos privados e das sociedades de crédito, financiamento e investimento, esta fonte assumiu grande importância, com a elevação da taxa sobre os depósitos à vista dos bancos, na medida em que escasseiam os recursos do tesouro nacional federal.

É importante saber que o governo também exercia controle sobre a taxa de juros cobrada sobre os empréstimos concedidos aos estabelecimentos rurais, conforme destacado por Gonçalves Neto $(1997$, p.165) “[...] a legislação estabelecia que a taxa de juros ao setor rural não poderia ultrapassar a três quartos das taxas aplicadas no mercado financeiro para outras atividades econômicas". Silva (1998) comenta que o subsídio agrícola daquele momento instituía-se na forma das taxas de juros nominais prefixadas, garantidas pelo Sistema Nacional de Crédito Rural.

Para Accarini (1987) a função do crédito rural esteve associada ao ganho de eficiência produtiva no desenvolvimento da atividade agrícola, propiciando ao produtor maior acesso aos meios de produção e às tecnologias voltadas para o campo. Esse crédito pode ser classificado em três tipos: o primeiro refere-se ao crédito de custeio e está vinculado à formação de capital de giro, voltado para aquisição de insumos agrícolas. O segundo é o crédito de investimento, o qual é reservado para aquisição de bens de capital, tais como máquinas e obras de infraestrutura. E, por fim, o crédito de comercialização, que objetivava fornecer suporte financeiro no momento da venda da 
produção no mercado, possibilitando ao produtor escolher a melhor oportunidade para a efetivação da transação.

Os dados da Tabela 1 demonstram como a obtenção do crédito rural esteve distribuída nas regiões brasileiras nos anos de 1970, 1975 e 1980.

Tabela 1 - Crédito rural obtido nos anos 1970, 1975 e 1980, conforme a região do país.

\begin{tabular}{cccccc}
\hline Regiões & $\begin{array}{c}\mathbf{1 9 7 0} \mathbf{~ e m}(\text { Mil } \\
\text { Cr\$) }\end{array}$ & $\begin{array}{c}\text { 1975 em (Mil } \\
\text { Cr\$) }\end{array}$ & $\begin{array}{c}\text { 1980 em }(\text { Mil } \\
\text { Cr\$) }\end{array}$ & $\begin{array}{c}\text { Total (Mil } \\
\text { Cr\$) }\end{array}$ & $\begin{array}{c}\text { (\%) no } \\
\text { período }\end{array}$ \\
\hline Norte & 123.138 & 489.336 & 8.157 .300 & 8.769 .774 & 2,26 \\
Nordeste & 530.894 & 4.905 .949 & 61.717 .580 & 67.154 .423 & 17,34 \\
Sudeste & 1.670 .332 & 12.984 .345 & 117.876 .160 & 132.530 .837 & 34,22 \\
Sul & 1.440 .120 & 13.009 .084 & 113.126 .885 & 127.576 .089 & 32,94 \\
Centro-Oeste & 379.704 & 4.767 .330 & 46.153 .263 & 51.300 .297 & 13,24 \\
\hline Total & $\mathbf{4 . 1 4 4 . 1 8 7}$ & $\mathbf{3 6 . 1 5 6 . 0 4 5}$ & $\mathbf{3 4 7 . 0 3 1 . 1 8 9}$ & $\mathbf{3 8 7 . 3 3 1 . 4 2 1}$ & $\mathbf{1 0 0 , 0 0}$ \\
\hline
\end{tabular}

Fonte: adaptado de IBGE (2011a), IBGE (2011b) e IBGE (2011c).

Conforme registrado na Tabela 1 , nota-se que a região brasileira que mais obteve crédito rural nos anos mencionados foi a Sudeste, consumindo o equivalente a $34,22 \%$ do total utilizado no período, seguida pela região Sul com 32,94\%, região Nordeste com 17,34\%, região Centro-Oeste com 13,24\% e, por último, a região Norte com apenas 2,26\% em relação ao volume total. Entretanto, analisando os dados sob a ótica da variação de crescimento dos recursos obtidos, nota-se que a região que mais cresceu nesse intervalo de tempo foi a região Centro-Oeste. Quando comparado o valor de crédito utilizado em 1970 com o ano 1980, observa-se que foi 121,55 vezes maior.

Tabela 2 - Crédito rural obtido nos anos de 1970, 1975 e 1980, conforme a modalidade.

\begin{tabular}{cccccc}
\hline Períodos & $\begin{array}{c}\text { Crédito para } \\
\text { investimento } \\
\text { em (Mil Cr\$) }\end{array}$ & $\begin{array}{c}\text { Crédito para } \\
\text { custeio em (Mil } \\
\text { Cr\$) }\end{array}$ & $\begin{array}{c}\text { Crédito para } \\
\text { comercialização } \\
\text { (Mil Cr\$) }\end{array}$ & $\begin{array}{c}\text { Crédito p/ dois } \\
\text { ou mais fins em } \\
\text { (Mil Cr\$) }\end{array}$ & $\begin{array}{c}\text { Total do } \\
\text { Crédito no } \\
\text { período em } \\
\text { (Mil Cr\$) }\end{array}$ \\
\hline 1970 & 1.077 .567 & 1.762 .529 & 127.674 & 1.176 .417 & 4.144 .187 \\
1975 & 7.240 .781 & 14.164 .409 & 500.508 & 14.250 .347 & 36.156 .045 \\
1980 & 47.757 .244 & 177.947 .530 & 3.815 .910 & 117.510 .505 & 347.031 .189 \\
\hline Total & $\mathbf{5 6 . 0 7 5 . 5 9 2}$ & $\mathbf{1 9 3 . 8 7 4 . 4 6 8}$ & $\mathbf{4 . 4 4 4 . 0 9 2}$ & $\mathbf{1 3 2 . 9 3 7 . 2 6 9}$ & $\mathbf{3 8 7 . 3 3 1 . 4 2 1}$ \\
\hline
\end{tabular}

Fonte: adaptado de IBGE (2011a), IBGE (2011b) e IBGE (2011c). 
A Tabela 2 apresenta os volumes de recursos financeiros obtidos pelos produtores nos anos de 1970, 1975 e 1980, classificados de acordo com a modalidade do crédito.

Com base nos dados da Tabela 2, e considerando os volumes de créditos utilizados para as atividades de investimento, custeio e comercialização, nota-se que a maior parte dos recursos foi empregada no custeio agrícola - valor equivalente a $50,05 \%$ do volume total nos anos analisados, ou seja, um indicativo de que mais da metade dos financiamentos esteve aplicada na compra de insumos, tais como fertilizantes, defensivos, sementes, combustíveis, lubrificantes, mão de obra, dentre outros.

Nota-se também que a modalidade de crédito que apresentou o menor índice de utilização foi o crédito para comercialização. Entretanto, Szmrecsányi (apud BELLUZZO; COUTINHO, 1998, p. 259) apresenta uma justificativa que esclarece tal fato "A exígua participação relativa do crédito de comercialização pode ser atribuída ao fato de tais operações serem também contempladas pela política de preços mínimos”.

Accarini (1987) ainda esclarece que o fornecimento de crédito rural no Brasil ocorreu por meio de dois fornecedores, denominados supridores institucionais e supridores informais. O primeiro se estabelece por intermédio das instituições financeiras, por meio dos bancos oficiais do Estado ${ }^{6}$, os bancos privados, as caixas econômicas e as cooperativas de crédito, além dos demais estabelecimentos devidamente autorizados pelo governo para concessão do recurso. O segundo ocorreu através dos comerciantes, atravessadores, exportadores e pelas indústrias de insumos agrícolas, e era comumente concedido aos produtores de pequeno porte ou àqueles que não dispunham de terras para dar em garantia ao pagamento da dívida aos fornecedores.

Gonçalves Neto (1997) ressalva que o crédito informal estabeleceu um significativo grau de importância no sistema de produção agrícola brasileiro até meados da década de 1960, quando então o Estado passou a estimular o processo de modernização da agricultura no país.

\footnotetext{
6 “Através do Decreto n 58.380 de 10.05 .66 o governo regulamentou a Lei que institucionalizou o crédito rural, estabelecendo o Banco Central - BACEN, Banco do Brasil, Banco da Amazônia - BASA e o Banco do Nordeste como instituições financeiras básicas do crédito rural, assim como o Banco de Crédito Cooperativo" (ARANTES; BASTOS apud PEREIRA, 2004, p. 671).
} 
Observa-se que a maior parte do volume de crédito rural obtido entre as décadas de 1970 e 1980 foi disponibilizada pelas instituições governamentais, por meios dos bancos oficiais do Estado, conforme apresentado na Tabela 3.

Tabela 3 - Comparação do volume de crédito rural obtido de origem governamental em relação às demais entidades nos anos de 1970, 1975 e 1980.

\begin{tabular}{ccccc}
\hline Períodos & $\begin{array}{c}\text { Crédito } \\
\text { governamental em } \\
\text { (Mil Cr\$) }\end{array}$ & $\begin{array}{c}\text { Crédito das demais } \\
\text { entidades em (Mil } \\
\text { Cr\$) }\end{array}$ & $\begin{array}{c}\text { Total dos créditos } \\
\text { obtidos em (Mil Cr\$) }\end{array}$ & $\begin{array}{c}\text { \%) do crédito de } \\
\text { origem } \\
\text { governamental }\end{array}$ \\
\hline 1970 & 3.270 .743 & 873.444 & 4.144 .187 & 78,92 \\
1975 & 30.273 .719 & 5.882 .326 & 36.156 .045 & 83,73 \\
1980 & 301.056 .878 & 45.974 .311 & 347.031 .189 & 86,75 \\
\hline
\end{tabular}

Fonte: adaptado de IBGE (2011a), IBGE (2011b) e IBGE (2011c).

As informações da Tabela 3 reforçam a crescente participação do Estado brasileiro no fomento ao crédito rural entre as décadas de 1970 e 1980 . No último período analisado, comprova-se que o volume de recursos utilizados é quase a totalidade de origem governamental.

Gonçalves Neto (1997) justifica que a baixa participação dos bancos comerciais na concessão de crédito rural explica-se pelo baixo domínio por parte dessas instituições sobre as variáveis que envolvem a atividade agrícola, tida como exógena, e, portanto, esses recursos eram destinados apenas a produtores que dispunham de vasta garantia para fornecer em troca do empréstimo, permitindo, assim, a redução do risco de negócio na operação financeira.

Especifica-se que a farta concessão do crédito rural no Brasil não ocorreu de forma sistemática no decorrer do tempo, conforme comentado por Bacha (2004, p. 63),

[...] o volume de crédito rural concedido expandiu-se significativamente a partir da segunda metade da década de 60 . A década de 70 presenciou grande expansão do volume de crédito rural, que se reduziu significativamente no início da década de 80, retomando valores crescentes em 1985 e 1986. A partir de 1987, o volume de crédito rural decresceu até o início da década de 90 , estabilizando-se, até 1994, em valores próximos aos vigentes no início da década de 70. Em 1995 e 1996, ocorreu nova forte redução no volume concedido de crédito rural, com recuperação parcial de 1997 a $2002[\ldots]$. 
A justificativa para a redução do volume de crédito rural iniciada a partir da década de 1980 está em um conjunto de fatores que se estabeleceram em cadeia, motivados principalmente pelo processo inflacionário ocorrido no país naquele instante, e combinado com a aplicação de medidas de restrição orçamentária determinada pelo Fundo Monetário Internacional (FMI), além de uma forte redução do quantitativo dos depósitos à vista realizados nos bancos comerciais. Tais fatos culminaram com a substituição das taxas de juros prefixadas, tidas como subsídio, pelas taxas pós-fixadas, incididas pelo índice de correção monetária, colocando o crédito agrícola em condições semelhantes aos demais tipos de créditos concedidos pelas instituições financeiras (SILVA, 1998).

\subsection{A política de garantia de preços mínimos}

Em paralelo ao sistema de financiamento rural, essencialmente promovido pelo Estado brasileiro a partir de meados da década de 1960, a Política de Garantia de Preços Mínimos (PGPM) apresenta-se como uma alternativa aos produtores agrícolas no momento da comercialização da produção gerada no campo, estabelecendo-se basicamente pela ação governamental na compra do excedente ou pelo financiamento da armazenagem dos produtos. Essa política é fundamentalmente aplicada em momentos de instabilidade de preços dos produtos de base agrícola.

A origem da PGPM foi demonstrada por Bacha (2004, p. 67): "Em 1943, foi criada a Comissão de Financiamento da Produção (CFP), transformada atualmente na Companhia Nacional de Abastecimento (Conab). Junto com a CFP foi instituída a Política de Preços Mínimos [...]”. Contudo, nota-se que a consolidação desse instrumento como meio de financiamento rural torna-se mais expressivo após a criação da SNCR em 1966.

O mecanismo de absorção do excedente de produção agrícola por parte do Estado pode ser mais bem explanado conforme a colocação de Accarini (1987, p. 142),

[...] o programa de preços mínimos pode cumprir seus objetivos básicos de estimular e orientar a produção rural e proteger a renda dos produtores. Em sua versão mais usual, esse programa consiste em o governo estabelecer preços aos quais poderá comprar determinados produtos caso não encontrem melhor alternativa no mercado. Nessas circunstâncias, o produtor armazena seus excedentes de produção em local devidamente credenciado, providencia a respectiva classificação e, após cumprir algumas formalidades, vende-os ao governo pelo 
preço fixado. Em caso contrário, tais excedentes são vendidos normalmente no mercado.

A aplicação da política de garantia de preços mínimos basicamente apresenta-se por intermédio da utilização de dois instrumentos, conhecidos como Aquisições do Governo Federal (AGF) e Empréstimos do Governo Federal (EGF). O primeiro se estabelece pela compra direta do produto agrícola do produtor rural, agricultor familiar ou até mesmo da cooperativa agrícola a que pertencem. Já a EGF corresponde a uma linha de crédito rural destinada especificamente para o financiamento do armazenamento da produção agrícola, objetivando a venda futura em melhores condições de preços. Todavia, é importante ratificar que ambos os instrumentos somente serão aplicados aos produtos pertencentes à pauta da PGPM.

Gonçalves Neto (1997) reforça que a política de garantia de preços mínimos apresenta-se ao produtor como um instrumento que se propõe a reduzir os riscos ou as incertezas incorridas no exercício da atividade agrícola, viabilizada pela estabilização, tanto no nível de preço, quanto no nível de renda, possibilitando ao produtor uma melhor análise sobre o aspecto do planejamento no momento que antecede o plantio.

Accarini (1987) explica que a dinâmica de compra e financiamento do armazenamento da produção por parte do governo provoca no mercado uma redução da oferta dos produtos contidos na pauta da PGPM e, por conseguinte, os preços tendem a reagir positivamente, permitindo, assim, a estabilização dos níveis de preços e, por consequência, dos níveis de renda, beneficiando não apenas os produtores participantes dessa política, bem como os demais.

[...] a política de crédito rural subsidiado não apenas permitiu reunificar os interesses das classes dominantes em torno da estratégia de modernização conservadora da agropecuária brasileira, como também possibilitou ao Estado restabelecer o seu poder regulador macroeconômico mediante uma política monetário-financeira expansionista. Não é sem outra razão que a política de crédito rural é considerada o carro-chefe da política de modernização conservadora até o final dos anos 70. (SILVA, 1998, p. 51)

Enfim, a aplicação de determinado conjunto de políticas direcionadas para a atividade agrícola apresenta-se entre as décadas de 1960 e 1970 como um fator determinante ao processo de modernização das estruturas agrícolas. 


\subsection{A política cambial}

Confere-se que a adoção de outras políticas de origem governamental, situadas nesse mesmo período, também estimulou o processo de modernização agrícola.

Assim, é possível também referenciar o sistema de minidesvalorização cambial, que, em conformidade com Bacha (2004), teve início ainda em 1968, perdurou até o começo de 1990 e tinha como propósito a inferência na taxa de câmbio por meio de pequenas desvalorizações da moeda corrente em relação ao dólar, inseridas em curtos espaços de tempo. Um dos objetivos dessa ação era o equilíbrio entre o controle inflacionário e a manutenção da balança comercial brasileira.

Na década de 1960 ocorreram significativas mudanças nas políticas econômicas e comerciais do país, que, até então, se estruturavam na questão da substituição das importações a fim de promover o aquecimento do mercado interno. No entanto, a partir de 1968, esse cenário sofre alterações, graças às políticas de minidesvalorização cambial e a isenção fiscal para a exportação de produtos industrializados. Porém, os produtos agrícolas não se beneficiaram do subsídio tributário, mas sim da política de intervenção cambial, permitindo ao setor auferir ganhos advindos da elevação dos preços de produtos agrícola, ocorridos na década de 1970 (GONÇALVES NETO, 1997).

Vasconcellos e Garcia (2004) lembram que a taxa de câmbio exerce um forte domínio sobre o resultado da balança comercial, devido a sua influência sobre os preços dos produtos de origem interna e externa. Desse modo, em um regime de desvalorização cambial a moeda local se deprecia em relação à moeda estrangeira e, portanto, criam-se condições favoráveis ao processo de exportação.

\subsection{A expansão da rede rodoviária}

Outro fator também determinante ao processo de modernização das estruturas agrícolas brasileiras, especialmente para a região Centro-Oeste, refere-se à expansão da rede de transporte rodoviário no país, ocorrida essencialmente a partir do final da década de 1950. Esse acontecimento, segundo o DNIT (2011), foi motivado por um conjunto de fatores ligados à implantação da indústria automobilística e à construção de Brasília. 
Teixeira e Hespanhol (2006, p. 57) referem-se à construção da nova Capital Federal como "[...] fato marcante na ocupação do Centro-Oeste, visto que acentuou o investimento em infraestrutura, principalmente no que se refere à ligação dessa cidade com os principais centros urbanos e produtivos do país".

Na Tabela 4 são apresentados os dados referentes à expansão da malha rodoviária brasileira, na qual são computados os dados das estradas municipais, estaduais e federais no período de 1955 a 1975.

Tabela 4 - Expansão da malha rodoviária entre as décadas de 1955 e 1975.

\begin{tabular}{cccc}
\hline Períodos & $\begin{array}{c}\text { Malha rodoviária } \\
\text { pavimentada em }(\mathbf{K m})\end{array}$ & $\begin{array}{c}\text { Malha rodoviária não } \\
\text { pavimentada }(\mathbf{K m})\end{array}$ & $\begin{array}{c}\text { Total da malha } \\
\text { rodoviária }(\mathbf{K m})\end{array}$ \\
\hline 1955 & 3.133 & 456.581 & 459.714 \\
1960 & 13.357 & 463.581 & 476.938 \\
1965 & 26.546 & 776.522 & 803.068 \\
1970 & 49.263 & 990.516 & 1.039 .779 \\
1975 & 64.744 & 1.363 .963 & 1.428 .707 \\
\hline
\end{tabular}

Fonte: adaptado de IBGE (2011d).

Os dados da Tabela 4 demonstram que num período de 20 anos o total da malha rodoviária brasileira esboçou um crescimento de 210,78\%, destacando-se, nesse contexto, a ampliação da malha rodoviária pavimentada, que evoluiu em 1.966\%, contra $198,73 \%$ da malha não pavimentada, no mesmo período.

Conforme apresentado por Brasil (2011), as obras de infraestrutura rodoviária que tinham por objetivo promover o desenvolvimento das regiões Norte e Centro-Oeste concentraram-se na construção dos seguintes trechos de rodovias: Cuiabá (MT) a Santarém (PA); Manaus (AM) a Porto Velho (RO); Cuiabá (MT) a Campo Grande (MS); Cuiabá (MT) a Goiânia (GO); Cuiabá (MT) a Porto Velho (RO); Cristalina (GO) a Catalão (GO); Rio Verde (GO) a Itumbiara (GO); e Dourados (MS) a Paranavaí (PR).

[...] O esforço do Governo Federal em dotar a região Centro-Oeste de uma infraestrutura de transportes adequada tem sido grande: a abertura de rodovias não pavimentadas no Centro-Oeste cresceu de 6 vezes mais que a média brasileira no período $1966 / 75$, e as pavimentadas desenvolveram-se duas vezes mais rápido que no resto do país. (PINA apud PEREIRA, 2004, p. 410) 
Para Bacha (2004, p. 157), "Esse crescimento e melhoria do sistema de transporte rodoviário permitiu acesso a novas regiões como Centro-Oeste e Norte. Essas duas regiões, em especial o Centro Oeste, constituíram a nova fronteira agrícola a partir dos anos 70".

\subsection{A pesquisa e a extensão rural}

A história da pesquisa agrícola no Brasil inicia-se ainda no final do período colonial e transcorre durante toda a fase imperialista, porém somente no início do século $\mathrm{XX}$ é que as políticas voltadas para esse segmento começaram a ser formuladas de forma mais contínua e distribuída regionalmente, tendo como ponto de partida a recriação do Ministério da Agricultura em 1909, ora destituído em 1892. Naquele momento a coordenação das pesquisas públicas voltada para o meio agrícola passou a ser atribuída ao então Departamento Nacional de Pesquisa Agropecuária (DNPEA) e executada por vários institutos de pesquisa agropecuária, o que perdurou o ano de 1972 (BACHA, 2004).

Entretanto, conforme citado por Queiroz (apud PEREIRA; XAVIER, 2003, p. $60)$,

[...] em 07 de dezembro de 1972, através da lei $n^{\circ}$ 5.851, o Governo Federal cria a Empresa Brasileira de Pesquisa Agropecuária EMBRAPA, com Estatuto aprovado pelo Decreto $\mathrm{n}^{\circ} 72.020 / 73$, empresa pública, de direito privado, vinculada ao Ministério da Agricultura, com autonomia administrativa e financeira, nos termos do Decreto Lei ${ }^{\circ} 200 / 67$ e tem sua instalação plena em 26 de abril de 1973.

De acordo com Bacha (2004, p. 82) “A EMBRAPA é um órgão do Governo Federal a quem cabe promover e executar as tarefas de pesquisas agropecuárias no Brasil, integrando os Estados, instituições privadas e universidades envolvidas com pesquisas agropecuárias”.

Accarini (1987, p. 109) comenta que a EMBRAPA,

[...] propiciou a montagem de uma política coordenada, mediante a destinação de recursos específicos para essa área de pesquisa. Como se trata de uma empresa pública, seu maior supridor de recursos é o próprio governo, muito embora ela conte, ocasionalmente, com alguma ajuda externa sob a forma de transferência de recursos financeiros e de conhecimentos tecnológicos. 
Anteriormente à criação da EMBRAPA, mais especificamente no início da década de 1960, Gonçalves Neto (1997) menciona que a atuação do governo brasileiro no processo de inovação tecnológica no meio agrícola se restringia em incentivar o uso de tecnologias já experimentadas em outros países. Todavia, observa-se que naquele momento o país reclamava o surgimento de inovações que fossem complementares às já disponíveis, de modo que pudessem se adaptar às demandas regionais.

Para Gonçalves Neto (1997, p. 201) "Com a criação da EMBRAPA, o governo preenche uma grande lacuna na política para o setor rural. E os investimentos crescentes na empresa indicaram um real esforço de superação do atraso e do descaso com que tinha sido tratada a pesquisa até então".

Cabe ressaltar que o papel da EMBRAPA no contexto do desenvolvimento agrícola está situado no perímetro da pesquisa, restando ainda a outra etapa desse trabalho - preconizada pelos projetos de extensão rural e caracterizada pela disseminação ou a difusão das tecnologias geradas pelos estudos realizados.

Portanto, ao discorrer sobre o tema da pesquisa agrícola, demonstra-se a função da extensão rural, que, segundo Bacha (2004, p. 84), é compreendida pelo “[...] conjunto de atividades direcionadas a transmitir aos agricultores novos conhecimentos técnicos e comerciais a respeito de culturas e criação de animais. O extensionista é o indivíduo que faz a ligação entre o setor de pesquisa e o agricultor”.

Accarini (1987, p. 120) define de forma mais clara as atribuições da extensão rural no processo de desenvolvimento das atividades agrícolas,

Os extensionistas rurais complementam, portanto, as atividades dos centros de pesquisa públicos e privados, servindo como uma espécie de ponte entre diferentes produtores e, principalmente, entre os produtores e aqueles centros, com os quais precisam estar em permanente contato.

Para Gonçalves Neto (1997, p. 202) “[...] o serviço de extensão rural procura atingir os que são mais refratários à adoção. E estes se encontram exatamente entre os mais pobres, descapitalizados, com acesso a pouca informação e distantes dos centros urbanos $[\ldots] "$.

Os primeiros programas de extensão rural no Brasil foram identificados ainda na primeira década do século XX em Lavras (MG). No entanto, a estruturação desse 
sistema somente ocorreu de forma efetiva em 1948, após a criação da Associação de Crédito e Assistência Rural (ACAR). Essa instituição objetivava o fornecimento de crédito agrícola a produtores rurais de pequeno porte, entretanto, o fornecimento do recurso financeiro estava condicionado à supervisão técnica e econômica, proferida por profissionais qualificados nas áreas, de modo que pudesse proporcionar aos agricultores o acesso à adoção de tecnologia no desenvolvimento da atividade rural (BACHA, 2004).

Conforme informado por Bacha (2004), durante a década de 1950, o sistema de concessão de crédito agrícola vinculado à supervisão foi bastante difundido no país, e, em 1956, já estava presente em nove estados brasileiros. Foi quando, então, surge a necessidade da criação de uma instituição que pudesse coordenar as atividades das ACAR, constituindo-se nesse mesmo ano a Associação Brasileira de Crédito e Assistência Rural (ABCAR).

É importante ressaltar que em 1974 a ABCAR foi substituída pela Empresa Brasileira de Assistência Técnica e Extensão Rural (EMBRATER), e as ACAR estaduais, pela Empresa de Assistência Técnica e Extensão Rural (EMATER). Essas alterações são justificadas pela mudança de foco das novas instituições, haja vista que o papel delas estava, a partir de então, somente orientado ao desenvolvimento das atividades de assistência técnica e extensão rural, desvinculando-as do crédito rural (BACHA, 2004).

Outro fato relevante ao processo de modernização agrícola, principalmente para o estado de Goiás, refere-se à criação da Empresa Goiana de Pesquisa Agropecuária (EMGOPA), que, conforme apresentado por Cerqueira e Silva (apud PEREIRA, 2004, p. 266), tratava-se de

[...] uma empresa vinculada à secretaria de Agricultura do Estado de Goiás, dotada de personalidade jurídica de direito privado, autonomia administrativa e financeira e com objetivos, metas, planos e sistema operacional ajustado à filosofia da EMBRAPA. Com atribuições de promover, estimular, supervisionar, coordenar e executar atividades de pesquisa e experimentação agropecuária no Estado de Goiás, objetivando a adaptação e/ou a geração e difusão de tecnologia para os produtores, de importância econômico-social local e/ou nacional, trabalhando integrada com a EMATER-GO, Ministério da Agricultura (EMBRAPA), Secretaria de Agricultura do Estado de Goiás e Universidade Federal de Goiás, a fim de evitar a pulverização de recursos e a duplicação de atividades. 
Um dos principais objetivos da EMGOPA concentrava-se na coordenação da pesquisa agrícola voltada para os serviços de assistência técnica rural, tanto no âmbito público, quanto no privado, entretanto, observa-se que durante a década de 1970 essa relação se estabeleceu de forma mais estreita com o setor público, por intermédio da EMATER. Já a menor participação da iniciativa privada foi justificada pela pequena presença desse setor no exercício da atividade de extensão rural naquele período (QUEIROZ apud PEREIRA; XAVIER, 2003).

A estruturação da EMGOPA aconteceu de forma distribuída por meio da criação de diversas estações e campos de experimentação instalados em diversos municípios do estado, tais como: Rio Verde, Anápolis, Catalão, Santa Helena, dentre outros. Todos eles somavam 14 unidades voltadas inicialmente para o desenvolvimento da pesquisa sobre arroz, feijão, milho, soja, algodão, bovinos e posteriormente abrangendo outras áreas agrícolas. Nesse contexto, destaca-se também a realização de experimentos em conjunto com outras instituições ligadas à agropecuária, principalmente as cooperativas agrícolas (CERQUEIRA; SILVA apud PEREIRA, 2004).

Cerqueira e Silva (apud PEREIRA, 2004) ainda ressalvam que os recursos utilizados pela EMGOPA no desenvolvimento das pesquisas eram obtidos por meio de diversas fontes, estruturando-se,

[...] convenientemente, tanto em termos físicos/financeiros como em recursos humanos, valendo-se do apoio da EMBRAPA e dos programas Especiais do Governo Federal como Polocentro, Poloamazônia e Pergeb (Geoeconômica de Brasília), de alguns órgãos como a SUDEPE, FINEP, CNPq e de outras instituições públicas ou privadas. (p. 267)

A participação das instituições de pesquisa e extensão rural constituiu-se como elemento estratégico no processo de modernização agrícola em Goiás, possibilitando que os resultados oriundos das pesquisas pudessem chegar ao produtor rural, seja por intermédio de instituições públicas, seja privadas.

\subsection{Os programas de desenvolvimento}

O processo de modernização das estruturas agrícolas, não somente em Goiás, mas também nos demais estados da região Centro-Oeste brasileira, estabeleceu-se 
essencialmente por meio de incentivo do Governo Federal, através da implantação de políticas governamentais que permitiram a transposição da agricultura, caracterizada até então como tradicionalista, para uma fase que se apresentou pela adoção de tecnologia no campo, propiciando, dessa forma, a inclusão do Estado no contexto do desenvolvimento regional e nacional (ESTEVAM, 2004b).

Para Balsadi (apud CAMPANHOLA; SILVA, 2000, p. 191), “[...] é inegável que desde as décadas de 50 e 60 houve uma grande transformação da base produtiva da região Centro-Oeste como resultado da participação efetiva do Estado".

Teixeira e Hespanhol (2006) comentam que a evolução da atividade rural nos estados que compõem a região Centro-Oeste brasileira estruturou-se com base no apoio dos estabelecimentos de pesquisa e extensão rural, cooperativas e bancos, além dos programas de incentivo à modernização agrícola elaborados pelo Governo Federal, principalmente aqueles que estiveram incluídos no Primeiro Plano Nacional de Desenvolvimento (1972-1974) (I PND) e no Segundo Plano Nacional de Desenvolvimento (1975-1979) (II PND).

É importante e relevante que se ressalte que a coordenação das linhas de ação por parte do Governo Federal, que culminaram na modernização agrícola da região Centro-Oeste, ocorreu inicialmente através da criação de uma agência de desenvolvimento, denominada Superintendência de Desenvolvimento do Centro-Oeste (SUDECO), seguida pela implantação de uma série de Programas Federais, também conhecidos como Programas Especiais, que objetivavam a promoção do desenvolvimento socioeconômico dos estados e municípios (PEREIRA, 2004).

A SUDECO foi instituída ainda em 1967 e tinha como propósito a promoção do desenvolvimento socioeconômico dos estados que compõem o Centro-Oeste brasileiro, por meio da distribuição da atividade econômica e inserção de investimentos públicos e privados nas regiões abrangidas, objetivando a geração de empregos e distribuição espacial da população e atuando principalmente na orientação dos fluxos migratório ocorridos naquele período (PINA apud PEREIRA, 2004).

Os Programas Federais ou Especiais estavam essencialmente voltados para o desenvolvimento regional, conforme apresentado por Pereira (2004, p. 427), 
Acentua-se que os programas/projetos especiais, voltados para a agropecuária, têm sua gênese num plano maior, em que, na verdade, os governantes visam mesmo é o AGRONEGÓCIO. Este viabiliza o desenvolvimento nacional, estadual e local. Tal desenvolvimento traduz-se mais acentuadamente, de 30 anos para cá, na manutenção da sustentabilidade dos ecossistemas, no equilíbrio orçamentário e na busca de superávit, visando com esta postura assegurar uma vida melhor às futuras gerações.

Ainda em conformidade com Pereira (2004, p. 430), "Entende-se por PROGRAMAS ESPECIAIS algo a ser realizado para suprir alguma demanda existente num determinado setor, que está obstaculizando o Plano Nacional ou Estadual de Desenvolvimento do País ou do Estado".

Os Programas Especiais fizeram parte do primeiro e segundo Programa de Desenvolvimento Nacional, instituídos entre 1972 e 1979, e foram criados para solucionar problemas específicos nas mais diversas áreas da atividade rural. Eles tinham por princípio a diversificação da base produtiva por meio da expansão da fronteira agrícola, destacando-se dentre eles o Programa de Garantia da Atividade Agropecuária (PROAGRO), o Programa Nacional de Calcário Agrícola (PROCAL), o Programa Nacional de Conservação do Solo (PROSSOLOS), o Programa de Desenvolvimento Nacional de Pastagens (PRONAP), o Programa de Desenvolvimento da Pecuária de Corte (PRODEPE), o Programa de Estímulos Técnicos e Financiamento para o Desenvolvimento da Pecuária Leiteira (PROLEITE), o Programa Nacional de Armazenagem (PRONAGEM), o Programa de Desenvolvimento do Centro-Oeste (PRODOESTE), o Programa de Desenvolvimento do Cerrado (POLOCENTRO) além de outros (PEREIRA, 2004).

Dentre esses programas, é importante destacar o papel desempenhado pelo POLOCENTRO criado em 1975, que, conforme colocado por Teixeira e Hespanhol (2006, p. 60),

[...] incentiva a ocupação produtiva das áreas de cerrado. Esse plano atraiu pessoas principalmente do Sul e Sudeste, interessadas nas facilidades oferecidas pelo plano. As áreas antes compostas pelo cerrado deram lugar às culturas agrícolas, predominando, no início, do arroz acompanhando as pastagens para a pecuária bovina que manteve amplo predomínio ao longo das décadas posteriores.

A atuação do POLOCENTRO teve como principal objetivo a modernização da atividade agrícola nos estados da região centro-oeste e oeste de Minas Gerais, buscando 
solucionar problemas localizados, tidos como setoriais, e destinando recursos principalmente para os setores de infraestrutura, pesquisa agrícola e crédito rural. Os recursos aplicados para as obras de infraestrutura estavam focados nas áreas de armazenamento da produção, construção de estradas e fornecimento de energia. Com relação à pesquisa agrícola, ela foi orientada e conduzida por intermédio da EMBRAPA, e os resultados puderam ser observados pelo ganho de produtividade nos projetos desenvolvidos. Com relação ao crédito rural, observa-se que, dada a diversificação dos tipos de créditos, em conjunto com os subsídios dos juros, ele serviu de incentivo para a ocupação das áreas de cerrados (ESTEVAM, 1998).

Pereira (2004) menciona que uma das metas do programa consistia na inserção de aproximadamente um milhão de hectares de área de cerrado ao sistema produtivo de Goiás. Desse volume 60\% seriam destinados à atividade de lavoura, e os demais $40 \%$ seriam empregados no desenvolvimento da pecuária, beneficiando de forma direta e indireta o equivalente a 63 municípios goianos.

As ações do Governo Federal através da criação da SUDECO e dos Programas Especiais contribuíram de forma significativa para a transformação da estrutura de produção agrícola em Goiás, influenciando nas técnicas produtivas, e tendo como via a inserção de tecnologia no campo e por consequência o ganho de produtividade nas áreas produtoras.

\subsection{As transformações da atividade agrícola a partir da década de 1970}

A aplicação de um conjunto de Políticas de Estado direcionadas ao setor agrícola, como o crédito rural e os investimentos em pesquisa e extensão, provocou efeitos no início da década de 1970, por meio do emprego de tecnologias no desenvolvimento das atividades rurais, evidenciado principalmente pelo crescimento da utilização de maquinários e implementos, fertilizantes e defensivos químicos.

Bacha (2004) comenta sobre a importância do processo de modernização agrícola no país a partir da segunda metade da década de 1960,

Os anos de 1965 a 1986 constituíram um período de aceleração do processo de modernização da agropecuária brasileira, o qual foi impulsionado por diversas políticas direcionadas a estimular o crescimento deste setor. Houve mudanças na importância da agropecuária no processo de desenvolvimento do país, o que levou à 
alteração no desempenho de algumas funções normalmente atribuídas à agropecuária no processo de desenvolvimento de uma nação. (p. 155)

Em 1970 o país já contava com 4.924.019 estabelecimentos agrícolas, dos quais 253.132 localizavam-se na região Centro-Oeste, e 145.115, em Goiás ${ }^{7}$. Observa-se também que o número total de pessoas ocupadas no desenvolvimento das atividades rurais no território nacional equivalia a mais de 17,5 milhões (IBGE, 2011a).

A adoção de tecnologia agrícola no desenvolvimento das atividades rurais no período de 1970 a 1985 pode ser demonstrada pelo crescimento do número de tratores, arados e fertilizantes químicos utilizados na fazenda, conforme os dados apresentados nas Tabelas 5, 6 e 7.

Tabela 5 - Comparação dos estabelecimentos agrícolas que utilizavam maquinário em 1970

\begin{tabular}{cccc}
\hline Maquinário agrícola & Brasil & Centro-Oeste & Goiás \\
\hline Tratores & 165.870 & 10.340 & 5.692 \\
Arados de tração mecânica & 160.884 & 9.612 & 5.818 \\
Máquinas utilizadas no plantio & - & - & - \\
Máquinas utilizadas na colheita & 98.184 & 2.931 & 1.575 \\
\hline Totais & $\mathbf{4 2 4 . 9 3 8}$ & $\mathbf{2 2 . 8 8 3}$ & $\mathbf{1 3 . 0 2 5}$ \\
\hline
\end{tabular}

Fonte: adaptado de IBGE (2011a).

Tabela 6 - Comparação dos estabelecimentos agrícolas que utilizavam maquinário em 1985

\begin{tabular}{cccc}
\hline Maquinário agrícola & Brasil & Centro-Oeste & Goiás \\
\hline Tratores & 665.280 & 85.233 & 33.548 \\
Arados de tração mecânica & 585.698 & 71.916 & 29.459 \\
Máquinas utilizadas no plantio & 342.066 & 40.891 & 17.961 \\
Máquinas utilizadas na colheita & 110.420 & 14.257 & 4.674 \\
\hline Totais & $\mathbf{1 . 7 0 3 . 4 6 4}$ & $\mathbf{2 1 2 . 2 9 7}$ & $\mathbf{8 5 . 6 4 2}$ \\
\hline
\end{tabular}

Fonte: adaptado de IBGE (2011e).

\footnotetext{
${ }^{7}$ No período mencionado o espaço territorial de Goiás abrangia os atuais estados de Goiás e Tocantins.
} 
Tabela 7 - Comparação do número de estabelecimentos agrícolas que empregavam fertilizantes químicos no período compreendido entre 1970 e 1985.

\begin{tabular}{cccc}
\hline Regiões & $\begin{array}{c}\text { Número de } \\
\text { estabelecimentos em } \\
\mathbf{1 9 7 0}\end{array}$ & $\begin{array}{c}\text { Número de } \\
\text { estabelecimentos em } \\
\mathbf{1 9 8 5}\end{array}$ & $\begin{array}{c}\text { Variação no período } \\
(\%)\end{array}$ \\
\hline Brasil & 425.667 & 1.510 .640 & 254,89 \\
Centro-Oeste & 6.903 & 94.673 & $1.271,48$ \\
Goiás & 5.807 & 68.997 & $1.088,17$ \\
\hline
\end{tabular}

Fonte: adaptado de IBGE (2011a) e IBGE (2011e).

Com base nos dados apresentados nas Tabelas 5 e 6, é possível fazer uma análise mais abrangente do nível de adoção de máquinas e implementos agrícolas no desenvolvimento das atividades rurais. Nota-se que no período analisado o crescimento do número de tratores no Brasil correspondia a 301,09\%, os arados de tração mecânica, a 264,05\% e as máquinas utilizadas na colheita esboçavam uma variação de 12,46\%.

Observa-se que no mesmo período a região Centro-Oeste apresentou um crescimento bem acima da média nacional. A variação do número de tratores nessa região equivaleu a $724,30 \%$, de arados de tração mecânica a $648,19 \%$, e as máquinas utilizadas na colheita alcançaram 386,42\%. Em Goiás, nota-se também uma evolução superior ao desempenho da média do país, exprimindo um aumento de 489,39\%, $406,34 \%$ e $196,76 \%$, respectivamente.

Outro dado importante analisado refere-se à utilização de fertilizantes químicos. Nesse caso, nota-se que o crescimento do número de estabelecimentos agrícolas que utilizaram esse tipo de tecnologia é ainda maior na região Centro-Oeste, quando comparado ao índice de crescimento nacional, demonstrando uma variação superior a $1.200 \%$. Essa mesma situação também pode ser observada no estado de Goiás, onde a presença desse insumo agrícola esteve associada a um crescimento maior que $1.000 \%$ no mesmo período.

Estevam (2004a) considera que a diferença entre a agricultura tradicional e a moderna no Centro-Oeste brasileiro passou a ser evidenciada a partir da década de 1970, surgindo, assim, um novo modelo de estabelecimento agrícola, caracterizado por uma série de mudanças estruturais, baseadas na utilização de tecnologia agrícola, fundada na utilização intensiva do solo e no uso de insumos e maquinários agrícolas, 
cuja produção destina-se principalmente para comercialização, fornecendo elementos à especialização produtiva.

\section{Considerações finais}

Com base nas reflexões provocadas pela contribuição teórica dos autores aqui presentes, e na análise dos dados apresentados neste artigo, torna-se relevante destacar alguns pontos que tiveram considerável importância no contexto do processo de modernização das estruturas agrícolas no Centro-Oeste brasileiro.

Nesse sentido, constatou-se a participação do Estado, que se posicionou como principal agente indutor desse processo, destacando-se inicialmente pelas ações aqui entendidas como de ordem direta, que se refere, nesse caso, à constituição da Superintendência de Desenvolvimento do Centro-Oeste, a SUDECO. Além disso, também pela criação dos diversos programas de incentivo ao desenvolvimento socioeconômico dos estados e municípios da região, como os Programas Especiais, com forte ênfase ao POLOCENTRO, que contribuiu de forma significativa para a formação da infraestrutura necessária ao progresso da atividade rural.

Já as ações de ordem indireta foram entendidas como o conjunto de políticas que tinham como objeto a promoção do desenvolvimento agrícola em âmbito nacional, mas que, de certa forma, tiveram um importante papel para o Centro-Oeste, como a política de crédito rural e preços mínimos, a política cambial, a pesquisa e extensão rural, por meio da criação da Embrapa, e, por conseguinte, a expansão da rede rodoviária, como a BR-452, ligando Rio Verde-GO a Itumbiara-GO, que permitiu a integração do sul e sudoeste de Goiás aos estados da região Sudeste do país.

E, por fim, verificou-se que a efetividade de tais políticas culminou num exponencial crescimento do uso de tecnologias no desenvolvimento das atividades no campo, essencialmente percebido pela utilização de máquinas e implementos e pelo emprego de fertilizantes químicos, o que resultou na transposição da agricultura até então caracterizada como tradicional para um modelo baseado na especialização produtiva. 


\section{REFERÊNCIAS}

ACCARINI, J. H. Economia rural e desenvolvimento: reflexões sobre o caso brasileiro. Petrópolis: Vozes, 1987. 224p.

ARANTES, P. F.; BASTOS, J. F. R. Crédito agropecuário e sua importância no processo de desenvolvimento de Goiás. In: PEREIRA, A. A. (Org.). Agricultura de Goiás: análise \& dinâmica. Brasília: UCG, 2004. p. 669-678.

BACHA, C. J C. Economia e política agrícola no Brasil. São Paulo: Atlas, 2004. $232 \mathrm{p}$.

BALSADI, O. V. Evolução das ocupações não agrícolas no meio rural goiano: 19811997. In: CAMPANHOLA, C.; SILVA, J. G. da (Org.). O novo rural brasileiro: uma análise estadual: Sul, Sudeste e Centro-Oeste. Brasília: Embrapa Meio Ambiente, 2000. p. 189-217.

BRASIL. Ministério dos Transportes. Evolução histórica do Ministério dos Transportes. Disponível em: <http://www.transportes.gov.br/index/conteudo/id/37613>. Acesso em: 2 fev. 2011.

CERQUEIRA, W. P.; SILVA, R. J. da. A EMGOPA e sua participação no desenvolvimento da pesquisa agropecuária em Goiás. In: PEREIRA, A. A. (Org.). Agricultura de Goiás: análise \& dinâmica. Brasília: UCG, 2004. p. 263-278.

DNIT. Departamento Nacional de Infraestrutura de Transportes. Breve histórico sobre a evolução do sistema nacional de transportes. Disponível em: <http://www.dnit.gov.br/planejamento-e-pesquisa/historico-do-planejamento-detransportes>. Acesso em: 2 fev. 2011.

ESTEVAM, L. Agricultura tradicional em Goiás. In: PEREIRA, A. A. (Org.). Agricultura de Goiás: análise \& dinâmica. Brasília: UCG, 2004a. p. 25-48.

Da agricultura tradicional à moderna. In: PEREIRA, A. A. (Org.). Agricultura de Goiás: análise \& dinâmica. Brasília: UCG, 2004b. p. 737-755.

O tempo da transformação: estrutura e dinâmica da formação econômica de Goiás. Goiânia: Ed. do Autor, 1998. 276p. 
GONÇALVES NETO, W. Estado e agricultura no Brasil: política agrícola e modernização econômica brasileira 1960-1980. São Paulo: Hucitec, 1997. 245p.

IBGE. Instituto Brasileiro de Geografia e Estatística. Censo Agropecuário Brasil 1970. Disponível em: <http://biblioteca.ibge.gov.br/visualizacao/monografias/GEBIS\%20\%20RJ/censoagropecuario/Censo\%20Agropecuario_1970_BR.pdf >. Acesso em: 22 jan. 2011a.

Instituto Brasileiro de Geografia e Estatística. Censo Agropecuário Brasil 1975. Disponível em: <http://biblioteca.ibge.gov.br/visualizacao/monografias/GEBIS\%20\%20RJ/censoagropecuario/Censo\%20Agropecuario_1975_BR.pdf >. Acesso em: 22 jan. $2011 b$.

Instituto Brasileiro de Geografia e Estatística. Censo Agropecuário Brasil 1980. Disponível

em:

$<$ http://biblioteca.ibge.gov.br/visualizacao/monografias/GEBIS\%20\%20RJ/censoagropecuario/Censo\%20Agropecuario_1980_BR.pdf>. Acesso em: 22 jan. 2011c.

Instituto Brasileiro de Geografia e Estatística. Censo Agropecuário Brasil 1985. Disponível em: <http://biblioteca.ibge.gov.br/visualizacao/monografias/GEBIS\%2020RJ/censoagropecuario/Censo\%20Agropecuario_1985_BR.pdf>. Acesso em: 22 jan. 2011e.

Instituto Brasileiro de Geografia e Estatística. Estatísticas Históricas do Brasil - Séries econômicas, demográficas e sociais 1550 a 1988. Disponível em: $<$ http://biblioteca.ibge.gov.br/visualizacao/monografias/GEBIS\%20$\% 20 \mathrm{RJ} /$ seriesestatisticasrestrospectivas/Volume\%203_Estatisticas\%20historicas\%20do \%20Brasil_series\%20economicas_demograficas\%20e\%20sociais\%20de\%201550\%20a \%201988.pdf>. Acesso em: 13 fev. 2011d.

PEREIRA, A. Programas Especiais de Desenvolvimento Agropecuário. In: PEREIRA, A. A. (Org.). Agricultura de Goiás: análise \& dinâmica. Brasília: UCG, 2004. p. 427452. 
PINA, R. O Centro-Oeste brasileiro e sua agência de desenvolvimento SUDECO. In: PEREIRA, A. A. (Org.). Agricultura de Goiás: análise \& dinâmica. Brasília: UCG, 2004. p. 407-526.

QUEIROZ, G. J. F. O papel do setor público na pesquisa agrícola de Goiás. In: PEREIRA, S. L.; XAVIER, C. L. (Org.). O agronegócio nas terras de Goiás. Uberlândia: EDUFU, 2003. p. 59-100.

SILVA, J. G. da. A nova dinâmica da agricultura brasileira. 2.ed. Campinas: Unicamp IE, 1998. 211p.

SZMRECSÁNYI, T. Análise crítica das políticas para o setor agropecuário. In: BELluZZO, L. G. de M.; COUTINHO, R. (Org.). Desenvolvimento capitalista no Brasil: ensaios sobre a crise. 4.ed. Campinas: Unicamp. IE, 1988. p.255-274.

TEIXEIRA, J. C.; HESPANHOL, A. N. A região Centro-Oeste no contexto das mudanças agrícolas ocorridas no período pós-1690. Revista Eletrônica da Associação dos Geógrafos Brasileiros - Seção Três Lagos, v. 1, n. 3, p. 52-66, maio 2006. Disponível em: <http://www.cptl.ufms.br/revista-geo/jodenir_antonio.pdf >. Acesso em: 16 fev. 2011.

VASCONCELLOS, M. A. S. de; GARCIA, M. E. Fundamentos de economia. 2.ed. São Paulo: Saraiva, 2004. 246p.

Recebimento dos originais: 08/06/2013

Aceitação para publicação: 15/08/2014 